\title{
Perancangan Exoskeleton untuk Terapi Range of Motion Pasif Lengan Atas Tahap Lanjut Penderita Stroke
}

\author{
Sherrine Hartono ${ }^{1}$, Dewanto Joni ${ }^{2}$ \\ 1,2 Program Studi Teknik Mesin Universitas Kris ten Petra \\ Jl. Siwalankerto 121-131, Surabaya 60236. Indonesia \\ *Penulis korespondensi; E-mail: m24415017@john.petra.ac.id¹, jdwanto@petra.ac.id²
}

\begin{abstract}
ABSTRAK
Pasien stroke biasanya mengalami gangguan motorik. Agar pasien stroke dapat mengembalikan kemampuan fisiknya, dilakukan fisioterapi. Fisioterapi untuk penderita stroke menggunakan latihan Range of Motion (ROM). Pada ROM pasif, energi yang dikeluarkan untuk latihan berasal dari orang lain (perawat) atau dapat juga dari alat mekanik. Karena itu, dirancang exoskeleton untuk membantu pasien stroke melakukan terapi ROM pasif untuk lengan atas. Dalam tugas akhir ini akan membahas perancangan exoskeleton mulai dari pembuatan konsep desain, analisa dan perhitungan elemen mesin, perancangan penyangga, dan perancangan sistem kontrolnya. Dari hasil perancangan diperoleh daya motor sebesar $0.12 \mathrm{~kW}$. Exoskeleton yang dirancang tersusung atas 2 buah mekanisme 4 batang, 2 buah poros, sabuk gilir, sepasang roda gigi, motor, penyangga, screw jack, dan swivel wheel. Untuk sistem kontrol menggunakan pengontrol mikro AVR, chip darlington, LCD, dan sensor opto-interrupt.
\end{abstract}

Kata kunci: Exoskeleton; range of motion; fisioterapi.

\begin{abstract}
Stroke patients usually experience motor problems. So that stroke patients can restore their physical abilities, physiotherapy is performed. Physiotherapy for stroke sufferers uses Range of Motion (ROM) exercises. In passive ROM, the energy expended for training comes from other people (nurses) or it can also be from mechanical devices. Therefore, an exoskeleton was designed to help stroke patients perform passive ROM therapy for the upper arm. In this final project, we will discuss the exoskeleton design starting from the conceptual design, analysis and calculation of machine elements, support design, and control system design. From the design results obtained the motor power of $0.12 \mathrm{~kW}$. The exoskeleton which is designed is supported by 2 4-rod mechanisms, 2 axles, a turning belt, a pair of gears, a motor, a support, a screw jack, and a swivel wheel. The control system uses an AVR micro controller, darlington chip, LCD, and an opto-interrupt sensor.
\end{abstract}

Keywords: Exoskeleton; range of motion; physiotherapy

\section{PENDAHULUAN}

Pasien stroke akan mengalami gangguangangguan motorik. Dari seluruh penderita stroke, mayoritas mengalami lumpuh sebagian atau bahkan lumpuh total, dan hanya sekitar $15 \%$ yang dapat sembuh total [1]. Dari seluruh pasien stroke yang mengalami kelumpuhan tubuh bagian atas, hanya $18 \%$ di antaranya dapat menggerakkan lengannya seperti semula. Agar pasien stroke dapat mengembalikan kemampuan fisiknya, dilakukan fisioterapi.

Fisioterapi untuk penderita stroke menggunakan latihan Range of Motion (ROM). Latihan ROM adalah latihan gerakan sendi yang memungkinkan terjadinya kontraksi dan pergerakan otot, dimana klien menggerakan masing-masing persendiannya sesuai gerakan normal [2]. Pada ROM pasif, energi yang dikeluarkan untuk latihan berasal dari orang lain atau alat mekanik [3].

Setelah pasien dapat dengan lancar melakukan latihan awal selama jangka waktu yang ditentukan, pasien dapat melakukan latihan ROM pasif tahap lanjut, biasa juga disebut sebagai Continuous Passive Motion. Gerakan yang dilakukan adalah dengan memutar secara perlahan lengan atas terhadap bahu dengan lingkaran penuh dalam keadaan lengan bawah horizontal dan pergelangan tangan tetap menghadap ke depan tubuh.

Beberapa studi telah membuktikan bahwa terapi lengan dengan exoskeleton membawa dampak positif terhadap proses rehabilitasi pasien-pasien stroke. Exoskeleton adalah suatu alat semacam pakaian tambahan yang bertujuan tidak hanya untuk melindungi, tetapi juga meningkatkan 
kemampuan penggunanya [4]. Beberapa mekanisme yang biasa digunakan untuk menggerakkan exoskeleton adalah sistem motor listrik, pneumatik, hidrolis, maupun kombinasi dari teknologi-teknologi tersebut.

Pada tahun 2011 dalam jurnal yang berjudul Mechanical Design of a Distal Arm Exoskeleton for Stroke and Spinal Cord Injury Rehabilitation, Ali Utku Pehlivan dan Ozkan Celik telah merancang desain exoskeleton robotik yang dinamakan MAHI Exo II untuk terapi lengan penderita stroke, cedera syaraf tulang belakang, dan penyakit syaraf lainnya [5]. Desain exoskeleton ini terdiri dari revolute joint di siku, 3-RPS (revolute-prismatic-spherical) di pergelangan tangan, dan dilengkapi dengan aktuator yang menggunakan motor DC.

Exoskeleton yang dirancang ini bukan seperti yang dimaksudkan Gregory S, Sawicki dkk, dalam papernya yang berjudul The exoskeleton expansion: improving walking and running economy [6]. Dalam penelitian ini, akan dirancang sebuah exoskeleton untuk terapi ROM pasif tahap lanjut penderita stroke yang dapat digunakan untuk menggerakkan lengan bagian bahu dan siku. Exoskeleton akan dirancang untuk dapat menahan beban lengan manusia yang besarnya 8 kilogram. Kecepatan rotasi ditentukan sebesar 10 RPM. Angka ini sesuai dengan anjuran kecepatan rotasi untuk terapi tahap lanjut ROM pasif lengan atas yaitu kira-kira 60 derajat per detik. Alat ini dirancang untuk dapat digunakan oleh penderita stroke yang lumpuh sebagian sehingga akan diberi penyangga yang dapat diatur ketinggiannya agar dapat disesuaikan dengan posisi duduk pengguna. Sistem kontrol akan dirancang agar pengguna dapat mengatur berapa banyak putaran yang akan dilakukan dan kecepatan putar.

\section{METODOLOGI}

\section{Pembuatan Konsep Desain}

Alat terapi lengan atas penderita stroke ini terdiri dari exoskeleton dan penyangganya. Exoskeleton dirancang untuk memutar bahu penderita stroke agar tidak mengalami pembekuan sendi. Untuk memutar bahu direncanakan menggunakan 4-bar mechanism seperti Gambar 1. Agar lengan bawah dapat berputar seperti spesifikasi yang diinginkan, maka diperlukan sabuk gilir untuk mengendalikan putaran. Untuk meneruskan daya dari motor ke poros digunakan roda gigi.

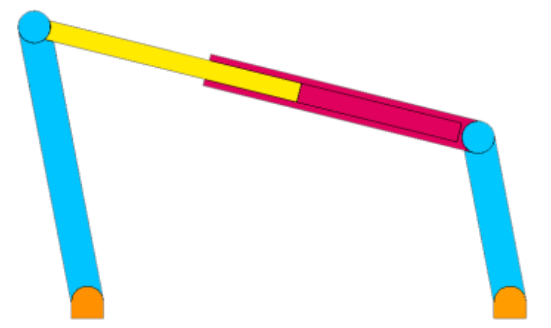

Gambar 1. Mekanisme 4 batang
Penyangga dirancang agar dapat disesuaikan tingginya sesuai dengan posisi duduk pengguna. Untuk itu digunakan screw jack untuk translasi penyangga. Penyangga juga menggunakan roda agar mudah dipindahkan. Tetapi roda yang digunakan harus dapat dikunci agar alat tidak bergerakgerak saat digunakan. Seperti nampak pada Gambar 2, maka komponen-komponen utama dari alat terapi ini terdiri dari:

- Mekanisme 4 batang

- Sabuk dan puli

- Roda gigi

- Motor

- Screw jack

- Roda

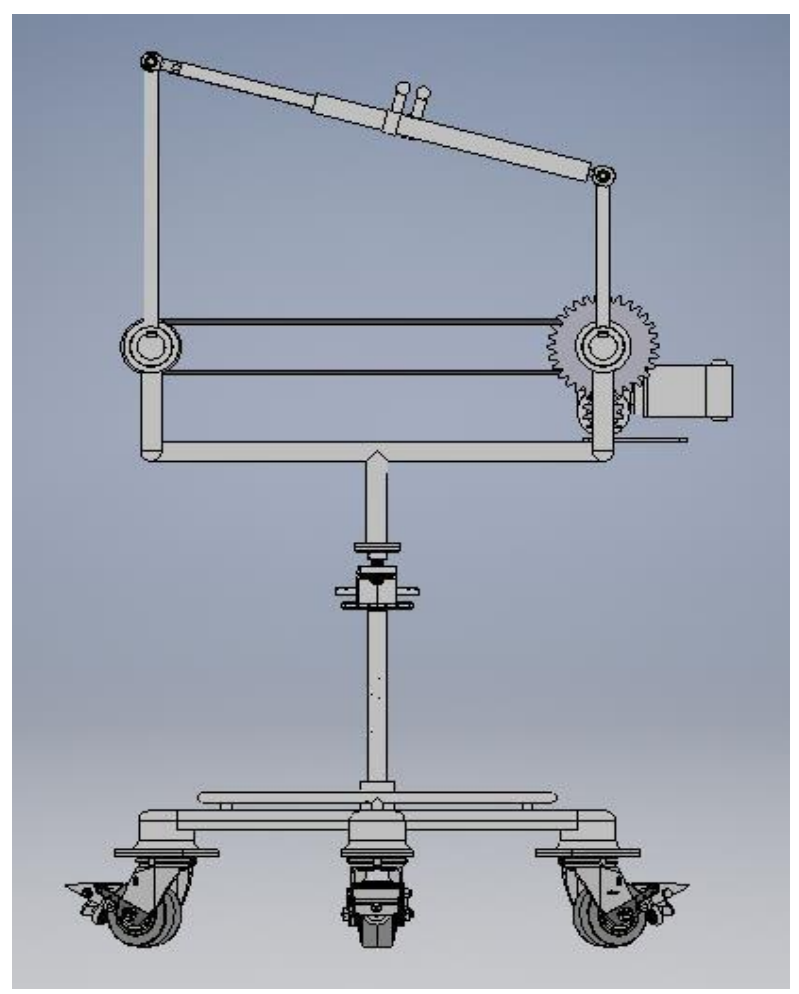

Gambar 2. Konsep desain exoskeleton dan penyangganya

\section{Perencanaan Komponen-Komponen Exoskele- ton dan Motor Penggerak}

- Perencanaan mekanisme 4 batang

Merencanakan dan menganalisa elemen-elemen mesin yang digunakan. Pertama-tama adalah menganalisa dimensi mekanisme 4 batang apakah dapat menahan tegangan yang ada. Analisa dilakukan dengan persamaan kesetimbangan gaya (F) dan momen (M) di tiap potongan batang $\sum^{(\text {Persamaan } 1):} F=0, \sum \mathrm{M}=0$

Tegangan yang terjadi pada setiap komponen dihitung berdasakan beban yang diterima kemudian dibandingkan dengan tegangan ijin (Persamaan 2)

$S_{Y P_{\text {izin }}}=\frac{S_{Y P}}{S F}$ 
Jika tegangan yang terjadi lebih kecil dari tegangan yang diizinkan, maka dimensi batang telah memenuhi syarat kekuatan komponen

- Perencanaan sabuk

Perencanaan sabuk menggunakan sabuk gilir untuk menghindari slip. Sabuk digunakan untuk menyamakan putaran antara poros utama dengan poros kedua. Kapasitas daya yang ditransmisikan per inch sabuk dapat dihitung menggunakan Persamaan 3.

$P_{o}=0.6984 \times 10^{-6}(D \times n)\left(F_{b 1}-F_{b 2}\right)$

Berdasarkan kapasitas daya maka didapatkan sabuk gilir yang digunakan adalah tipe L075. Panjang belt dapat dihitung dengan rumus pada Persamaan 4

$$
L=\left(\frac{z_{1}+z_{2}}{2}+2 C_{p}+\frac{\left[\left(z_{1}-z_{2}\right) / 6.28\right]^{2}}{C_{p}}\right) \times p
$$

- Perencanaan motor

Perencanaan motor diawali dengan mencari torsi yang dibutuhkan. Dalam perancangan ini, torsi yang dibutuhkan adalah dua kali torsi dari mekanisme 4 batang, dan torsi pada sabuk. Setelah itu dapat dihitung daya motor (Persamaan 5dan 6)

$$
\begin{aligned}
& \text { Nett Power }(\text { Pnett })=\tau \times \omega \\
& \text { Power }(\text { Pact })=\frac{\text { Pnett } \times S F}{\eta}
\end{aligned}
$$

Didapatkan daya motor yang dibutuhkan minimum 102 Watt.

- Perencanaan poros

Dalam perancangan ini, poros menerima beban bending $(\mathrm{Mb})$ dan torsi $(\mathrm{Mt})$. Untuk itu tegangan yang terjadi dihitung berdasarkan tegangan kombinasi dari kedua tegangan tersebut (Persamaan 7). Selanjutnya dibandingkan dengan tegangan ijin

$$
\sigma_{v}=\sqrt{\sigma_{b \max ^{2}+4 \tau_{t}^{2}}}
$$

$$
\text { Dimana } \sigma_{b \max }=\frac{M b}{\frac{\pi \times d^{3}}{32}}
$$

$$
\tau_{t}=\frac{M t}{\frac{\pi \times d^{3}}{16}} \quad \text { dan } \mathrm{d}: \text { Diameter poros }
$$

Jika tegangan yang terjadi lebih kecil dari tegangan yang diizinkan, maka dimensi poros telah memenuhi syarat kekuatan.

\section{Perencanaan Penyangga}

Penyangga dirancang menurut ketinggian penggunanya. Untuk itu, maka penyangga dirancang untuk memiliki tinggi minimum $910 \mathrm{~mm}$ dan tinggi maksimum $1075 \mathrm{~mm}$ [7].

Penyangga dirancang agar dapat diatur ketinggiannya. Untuk mengatur ketinggian maka digunakan screw jack. Screw jack dipilih untuk melakukan translasi sebesar $300 \mathrm{~mm}$.
Agar mudah dipindah-pindahkan, penyangga dirancang dengan menggunakan 3 kaki yang masing-masing dipasangi roda. Roda yang digunakan adalah jenis roda swivel. Agar saat penggunaan alat tidak bergerak-gerak, maka dipilih swivel wheel yang dapat dikunci.

\section{Merancang Sistem Kontrol}

Sistem kontrol dirancang untuk dapat menjalankan operasi berikut:

1. Motor berhenti pada awalnya. Pesan ditampilkan pada LCD untuk memasukkan jumlah rotasi motor yang diperlukan.

2. Pengguna dapat memilih jumlah rotasi yang diperlukan dengan menekan tombol 1 atau 2 . Tombol 1 digunakan untuk menambah jumlah rotasi sebanyak 5 dan tombol 2 adalah untuk mengurangi jumlah rotasi sebesar 5 .

3. Setelah jumlah rotasi yang diinginkan dipilih, pengguna harus menekan enter (tombol 3).

4. Setelah 2 detik, pengguna diminta untuk memasukkan kecepatan yang diperlukan.

5. Pengguna dapat mengatur kecepatan dari $10 \%$ hingga 100\% dalam langkah 10 dengan menekan tombol1 dan tombol2 yang sama. Tombol 1 digunakan untuk meningkatkan kecepatan sebesar $10 \%$ dan tombol 2 adalah untuk menurunkan kecepatan sebesar $10 \%$.

6. Setelah kecepatan keinginan diatur, lagi-lagi pengguna harus menekan enter.

7. Ketika pengguna menekan tombol putar (tombol 4), pengontrol mikro menerapkan PWM sesuai kecepatan yang dipilih untuk motor dan motor mulai berputar pada kecepatan yang diinginkan. LCD menunjukkan kecepatan dan putaran motor.

8. Ketika motor memutar satu putaran, sebuah strip yang terpasang pada poros motor melewati celah sensor opto-interrupt. Itu mengganggu cahaya IR yang jatuh pada transistor foto untuk sepersekian detik. Jadi foto transistor memberikan durasi pulsa positif yang sangat singkat. Pulsa positif ini dibalikkan oleh transistor NPN dan ini memberikan pulsa negatif durasi pendek. Denyut negatif ini menghasilkan interupsi untuk pengontrol mikro. Pengontrol mikro menghitung jumlah interupsi ini sebagai jumlah rotasi motor.

9. Ketika motor menyelesaikan jumlah rotasi yang diinginkan, pengontrol mikro berhenti menerapkan PWM sehingga motor berhenti.

\section{HASIL DAN PEMBAHASAN}

Dari analisa perencanaan elemen mesin, didapatkan bahwa motor yang digunakan adalah motor DC dengan daya 120 Watt. Sabuk yang digunakan adalah timing belt L075.

Untuk mengetahui apakah rancangan penyangga dapat menahan gaya-gaya dan tegangan yang ada 
maka dilakukan simulasi stress analysis menggunakan Autodesk Inventor (Gambar 3). Dari simulasi tersebut diketahui bahwa penyimpangan maksimum adalah sebesar $10.25 \mathrm{~mm}$, yang masih dapat ditoleransi. Oleh karena itu, disimpulkan penyangga yang dirancang dapat menahan gaya dan tegangan maksimum yang terjadi.

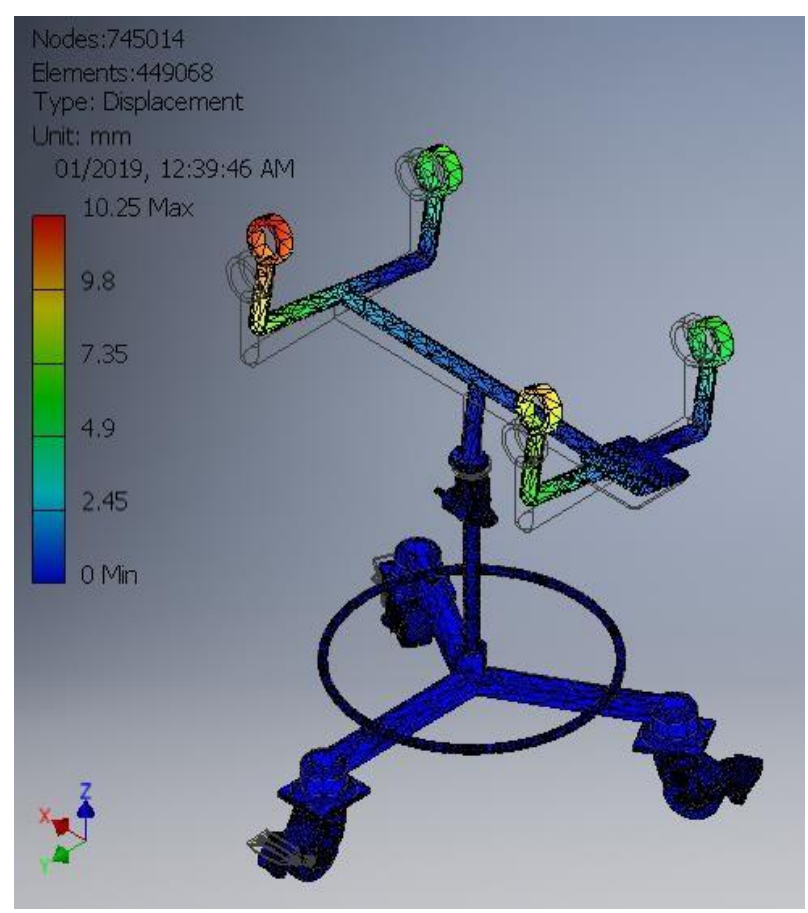

Gambar 3. Simulasi stress analysis penyangga

Sistem kontrol dirancang dengan sirkuit yang dibangun menggunakan micro-contoller AVR ATMega32, chip darlington ULN2003A, LCD, sensor opto-interrupt MOC7811 dan beberapa komponen lain seperti tombol tekan, resistor, dan sebagainya. Empat tombol ditekan terhubung ke pin PORTA PA0 - PA3 sehingga ketika tombol ditekan akan memberikan input logika '1' ke pin.

Tombol tersebut digunakan untuk memasukkan putaran dan kecepatan untuk memutar motor. LCD terhubung ke PORTC dan PORTD. Pin data terhubung ke PORTC dan dua pin kontrol Rs dan En masing-masing terhubung ke PD0 dan PD1. LCD menampilkan jumlah rotasi dan kecepatan motor DC. PORTD pin PD7 menggerakkan motor DC melalui chip Darlington ULN2003A. Pin ini terhubung ke input ULN2003A dan output ULN2003A terhubung ke satu terminal motor. Terminal motor lain terhubung ke suplai $12 \mathrm{~V}$. Sensor opto-interrupt MOC7811 internal terdiri dari IR LED dan foto transistor. Output dari transistor foto diberikan sebagai input ke transistor NPN lain yang terhubung dalam mode sakelar. Output akhir dari rangkaian sensor diambil dari kolektor transistor NPN. Output ini diberikan untuk interupsi eksternal input pin PD2 dari ATMega32. Diagram sistem kontrol dalam rancangan ini ditunjukkan pada Gambar 4

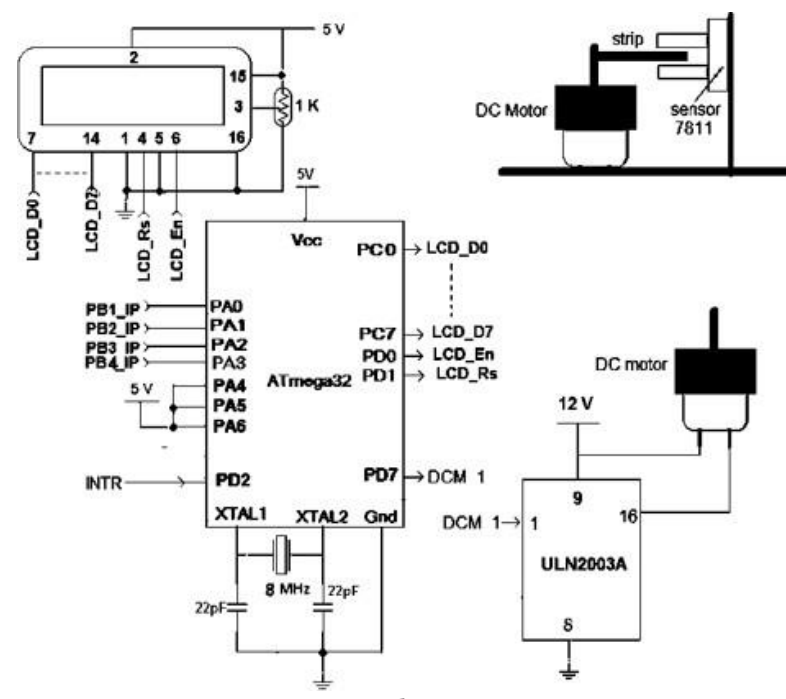

Gambar 4. Diagram sistem kontrol

\section{KESIMPULAN}

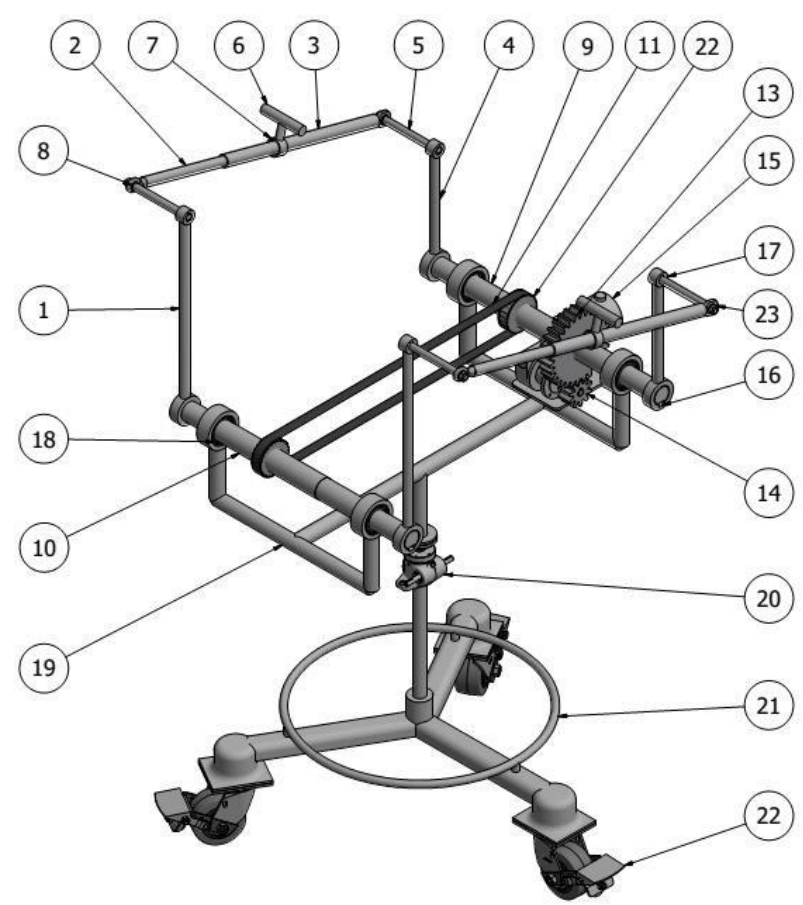

Gambar 5. Hasil rancangan exoskeleton

Exoskeleton untuk alat terapi lengan atas penderita stroke dirancang dengan komponen-komponen utama sebagai berikut:

1. Batang penghubung ke poros kedua

2. Batang slider

3. Batang penumpu lengan bawah

4. Batang penghubung ke poros utama

5. Link

6. Pegangan tangan (handle)

7. Clamp

8. Rod-end bearing

9. Poros utama

10. Poros kedua

11. Timing belt

12. Timing pulley 
13. Roda gigi poros utama

14. Roda gigi motor

15. Motor $0.12 \mathrm{~kW}$

16. Pasak besar

17. Pasak kecil

18. Bearing poros

19. Penyangga

20. Screw jack

21. Dasar penyangga

22. Swivel wheel

23. Mur

Untuk itu dengan realisasi rancangan ini maka para penyandang gangguan motorik dapat melakukan terapi pemulihan kesehatannya dengan mudah dan proporsional menurut tingkat kebutuhannya.

\section{DAFTAR PUSTAKA}

[1]. N. R. Wardhani, S. Martini. Faktor yang berhubungan dengan pengetahuan tentang stroke. [Online] from https://e-journal.unair.ac.id/ JBE/ article/download/149/23. (2014) [Acessed on 9 April 2018].
[2]. D. M. Bakara, S. Warsito. Latihan range of motion pasif terhadap rentang sendi pasien pasca stroke. (2016). Bengkulu: Kemenkes.

[3]. K. Suwartana. Range of motion. Bali: Stikes Bina Usada. (2012).

[4]. D. Akbar. Dibalik teknologi exoskeleton. [Online] from https://www.pcplus.co.id/2014/07/fitur/ dibalik-teknologi-exoskeleton/. (2014) [Acessed on 29 March 2018].

[5]. A. U. Pehlivan, O. Celik. Mechanical design of a distal arm exoskeleton for stroke and spinal cordinjury rehabilitation. [Online] from http://citeseerx.ist.psu.edu/messages/downloads exceeded.html. (2011) [Acessed on 9 April 2018].

[6]. Gregory S. Swicki at all, The exoskeleton expansion: improving walking and running economy, Journal of Neoroengineering and Rehabilitation, February 2020

[7]. C. C. Gordon. Anthropometric data : summary statistics report. [Online] from https://multisite. eos.ncsu.edu/www-ergocenter-ncsu-edu/wpcontent/uploads/sites/18/2016/06/Anthropometri c-Detailed-Data-Tables.pdf. (1988) [Acessed on 2 October 2018]. 